\title{
A Brief History of Industrial Robotics in the 20th Century
}

\author{
A. Gasparetto, L. Scalera \\ Polytechnic Department of Engineering and Architecture, University of Udine, Udine, Italy \\ Email: alessandro.gasparetto@uniud.it, scalera.lorenzo@spes.uniud.it
}

How to cite this paper: Gasparetto, A., \& Scalera, L. (2019). A Brief History of Industrial Robotics in the 20th Century. Advances in Historical Studies, 8, 24-35. https://doi.org/10.4236/ahs.2019.81002

Received: January 15, 2019

Accepted: February 12, 2019

Published: February 15, 2019

Copyright $\odot 2019$ by author(s) and Scientific Research Publishing Inc. This work is licensed under the Creative Commons Attribution International License (CC BY 4.0).

http://creativecommons.org/licenses/by/4.0/

\begin{abstract}
Industrial robotics is a branch of robotics that gained paramount importance in the last century. The presence of robots totally revolutionized the industrial environment in just a few decades. In this paper, a brief history of industrial robotics in the 20th century will be presented, and a proposal for classifying the evolution of industrial robots into four generations is set forward. The characteristics of the robots belonging to each generation are mentioned, and the evolution of their features is described. The most significant milestones of the history of industrial robots, from the 1950's to the end of the century, are mentioned, together with a description of the most representative industrial robots that were designed and manufactured in those decades.
\end{abstract}

\section{Keywords}

Industrial Robots, History, Unimate, Stanford Arm, Delta Robot

\section{Introduction}

The idea to design and build some sort of beings, or devices that could carry out repetitive or heavy tasks, thus relieving men from this burden, dates back to ancient times. Since the Greek-Hellenistic age some of these devices, which were named automata, have been designed and created by ingenious inventors, belonging to several different civilizations through the centuries. The term "automata" mainly refers to human-like devices, while the term "robot" has a more general meaning.

The origin of the term "robot" is placed in more recent times: namely, it comes from the Czech word "robota", meaning "heavy work" or "forced labour". The introduction of this term is due to the Czech writer Karel Čapek (1890-1938), who used it for the first time in 1920 in his novel "R.U.R.: Rossum's Universal Robots" (Čapek, 2004). 
On the other hand, the word "Robotics" was employed for the first time by Isaac Asimov (1920-1992) in his novel "Runaround" (1942), contained in the famous series "I, Robot". In that novel he defined three rules concerning the behavior of robots and the interaction with humans: these rules would later be named the three Laws of Robotics (Asimov, 1942).

In the literature, there are not so many works dealing with Robotics from a historical perspective. For instance, Ceccarelli dealt with this topic in (Ceccarelli, 2001) and (Ceccarelli, 2004), while Gasparetto (2016) presents a historical outline of robotics from ancient times until the Industrial Revolution.

Industrial applications of Robotics gained a paramount importance in the last century. The beginning of "Industrial Robotics", as we currently define it, can be dated back to the 1950's, although some kinds of automatization in the industrial environment started to appear since the times of the Industrial Revolution.

In this paper, the main milestones of the history of industrial robotics, from its beginning (in the 1950's and even earlier) to the end of the 20th century, will be mentioned and described.

The evolution of industrial robots can be subdivided in four categories, as in (Zamalloa, 2017), the first three covering the timespan from the 1950's to the end of the 1990's. The robots of the fourth generation (which ranges from 2000 to nowadays), that are characterized by high-level "intelligent" features (such as the capability of performing advanced computations, logical reasoning, deep learning, complex strategies, collaborative behavior), are not analyzed in this paper.

In the scientific literature, not so many works on the history of industrial robots are present. In some books, such as in (Ceccarelli, 2004), (Mathia, 2010), (Siciliano \& Khatib, 2008), and (Westerlund, 2000), there are some sketches on this topic, which could also be found in some internal reports, e.g. in (Lagerberg \& Jonson, 2016) and (Wallen, 2008).

\section{The First Generation of Industrial Robots (1950-1967)}

Some Authors (Zamalloa, 2017) proposed a chronological categorization of industrial robots, by defining four "generations".

The first generation of industrial robot spans from 1950 to 1967. The robots of this generation were basically programmable machines that did not have the ability to really control the modality of task execution; moreover, they had no communication with the external environment. With respect to the hardware, the first generation robots were provided with low-tech equipment, and servo-controllers were not present (Wallen, 2008). A peculiar feature of these robots is the strong noise they produced, when their arms collided with the mechanical stops built to limit the movement of the axes. With respect to the actuators, almost all the first generation robots employed pneumatic actuators and were controlled by a sort of "logic gates" acting as automatic regulators. Such "logic gates" were basically cams which activated pneumatic valves, or relays 
which controlled solenoid valves. Finally, the tasks that the first generation robots were capable to perform were necessarily quite trivial, such as loading-unloading or simple material handling operations.

The history of industrial robotics is conventionally set in the 1950's, although some developments in automation had taken place before: namely, a "programmable" paint-sprayer device invented by Pollard and Roselund in 1938 (Koetsier, 2019), and a tele-operated "manipulator" invented by Goertz in 1949, for instance. However, the turning point for industrial robotics was due to the genius of George Devol, who designed in 1954 a "Programmable Article Transfer" (this was the name given when the patent request (Devol, 1954) was filed). Such a device was the base for the development of Unimate, that is considered the first "true" industrial robot in history.

Devol (Malone, 2011), who was basically a scientist, needed an entrepreneurial mate with whom set up in a more concrete way his idea of a robotic manipulator which could be used to automatize industrial processes. In 1954 he met Joseph Engelberger, an engineer employed in the spatial industry, and they agreed on setting up a company which could manufacture robots for industrial applications. This led to the foundation of a company named Unimaton, which produced in 1961 the first Unimate robot (Figure 1). Unimate, which was hydraulically actuated, was immediately installed in an automotive company, namely in the General Motors factory located in Trenton (New Jersey, USA), where it was employed to extract parts from a die-casting machine (as mentioned earlier, it was used for a single task, because it was very complicated to reprogram it). In the following years, several other Unimates were installed in automotive factories, where were mainly employed for spot-welding of cars and for handling of workpieces (Wallen, 2008).

In the same years, several robot manufacturing companies were born, due to the fact that many entrepreneurs understood that this kind of devices had great potentialities, especially in the automotive sector. Companies like Ford and General Motors started to consider the automatization of their productive plants and needed device such as the new robot to achieve this goal. Thus, there was a sudden increase in the orders of robotic devices, which gave the opportunity to thrive to many robot manufacturers.

One of such companies was, for instance, AMF Corporation: in 1962 they manufactured a new robot that was called Versatran (i.e. "versatile transfer"). It was a cylindrical robot (Figure 2) that was ordered by Ford for its production plants in Canton (Ohio, USA), thus enjoying a good popularity (Birnie, 1974). The Versatran was also the first robot to be installed in a productive site in Japan (1967). In 1969, the presence of robots in Japanese companies had a significant increase, also due to the fact that Unimation allowed to Kawasaki Heavy Industries Ltd. the license to produce robots for the Japanese and the Asian market. In particular, this led to the development of the Kawasaki-Unimate 2000, the first industrial robot ever built in Japan. 


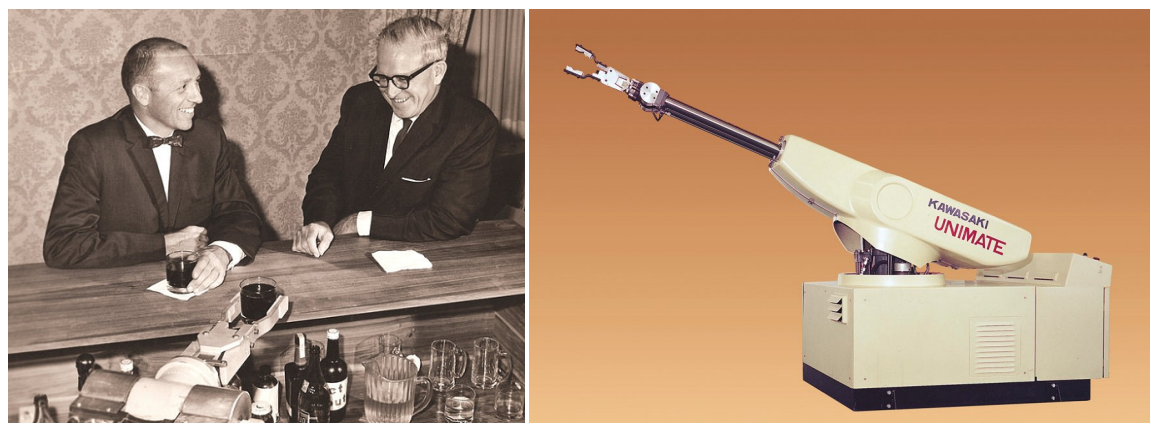

Figure 1. Joseph Engelberger and George Devol (left); the Unimate robot (right).

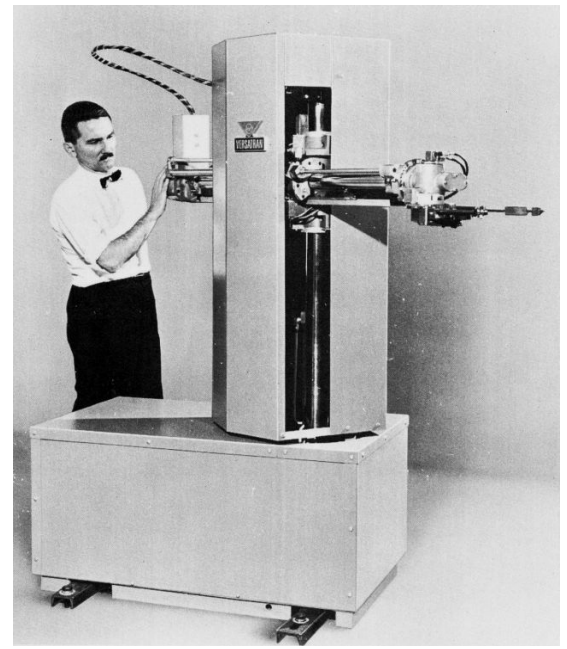

Figure 2. The Versatran robot.

Since then, Japan became one of the leading countries in the world in the field of industrial robotics. It was in Japan that the first national robotic association in the world was founded in 1971, namely JIRA (Japanese Robotics Association).

The diffusion of robots in Europe took place more or less at the same time as in Japan, namely in the second half of the 1960's. The first robotic installation in Europe appeared in 1967 in the company Svenska Metallverken located in Upplands Väsby (Sweden): it consisted of robots carrying out simple pick-and-place tasks (Wallen, 2008). Two years later, in Norway, the first painting robot was manufactured by the Tralffa Company and installed in a plant for wheelbarrow painting.

The appearance of robots allowed to automatize important production tasks such as welding. Unimation was the first company to manufacture welding robots, while General Motors was the first company to install this kind of robotic devices at their automotive plants in Lordstown (Ohio, USA) in 1969. Three years after, FIAT installed the first welding robots in Europe at their plants in Turin (Italy).

\section{The Second Generation of Industrial Robots (1968-1977)}

The industrial robots of the second generation (conventionally ranging from 
1968 to 1977) were basic programmable machines with limited possibilities of self-adaptive behavior and elementary capabilities to recognize the external environment (Zamalloa, 2017). These robots used servo-controllers, which enabled them to perform both point-to-point motion, and continuous paths as well. Their control system consisted of microprocessors or of Programmable Logic Controllers (PLC), and they could be also programmed by an operator by means of a teach box. With respect to those belonging to the first generation, these robots could carry out more complex tasks (e.g. control of work centers). However, their level of versatility was not very high, because each robot had its own software, which was dedicated to a specific task. Hence, these robots turned out to be application-specific devices, meaning that it was very difficult to employ the same robot for different tasks, since this would require a substantial modification of the controller, and a thorough reprogramming of the operating software. With respect to diagnostics, the robots of the second generation were not very performant, since the only diagnostic reports they could produce were those related to failures, which were reported by means of indicator lights, without any hint related to the cause of the failure that was left to the operator to trace.

At the beginning of the history of industrial robotics, the robots had hydraulic actuators. The shift from hydraulic to electric actuators took place in the 1970's, when the electronic components needed to govern a robot reached the full technical maturity. As a matter of fact, microprocessors and other components started to be widely used at that time: this allowed the robot manufacturers to dispose of powerful and cost-effective devices which could be employed to implement control systems able to deal with a complex and computationally expensive task such as the control of a robot.

The economic and geopolitical situation, at the international level, also pushed the trend towards electrically driven robots: for instance, the price of crude oil suddenly grew after the oil crisis following the Kippur war (October 1973). The companies were thus forced to find more efficient ways of production: robot (and in particular electrically driven robots) was consistent with the goals of reducing the costs and increasing the productivity. This gave a boost to the installations of industrial robots, which increased more than $30 \%$ per year in the second half of the 1970's (Karlsson, 1991).

From the scientific point of view, a significant base for the development of electrically driven robots was the merit of Victor Scheinman (Scheinman, 1973). Scheinman was a mechanical engineering student at Stanford University who in 1969 designed and built the famous Stanford Arm (Figure 3). This robot was the first prototype of a robot actuated by electric motors (6 DC motors) and controlled by a PDP- 6 microprocessor. The Stanford Arm had 5 revolute and one prismatic joint, for a total of 6 DOFs, and its kinematic chain was made of harmonic drives and spur gear reducers. Its inverse kinematics could be analytically solved in a closed form, which allowed a fast trajectory execution. Moreover, some sensors (tachometers and potentiometers) were mounted on the robot, in order to measure position and velocity of the robot joints. 


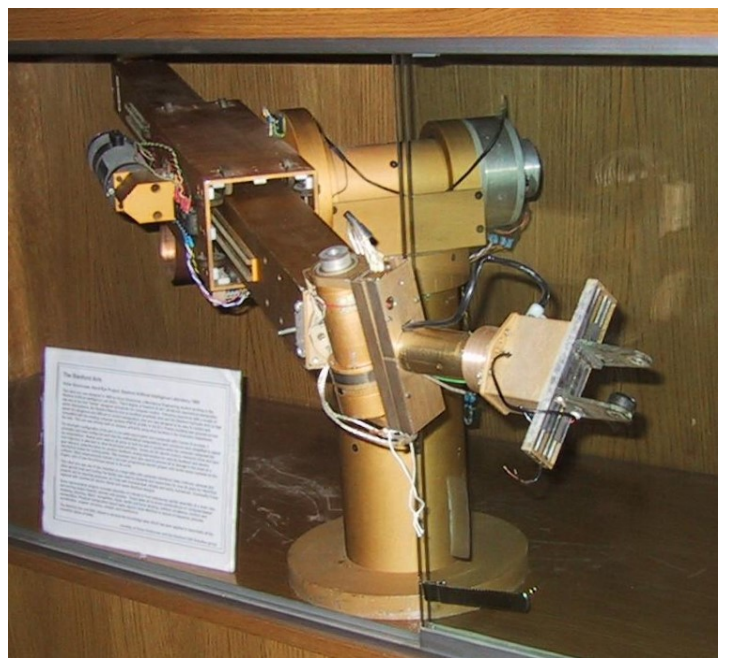

Figure 3. The Stanford Arm.

Four years later (1973), Scheinman designed another electrical robot, named Vicarm, that was smaller and lighter than the industrial robots of that time. This made Vicarm particularly suitable for use in tasks, such as assembly of parts, where the robot was not required to lift and carry heavy loads. These features of Vicarm were so appreciated, that Unimation bought the company that produced Vicarm and exploited its know-how to design and manufacture (in 1978) the famous PUMA robot (Figure 4).

The PUMA (an acronym for Programmable Universal Machine for Assembly) was considered for many decades the archetype of the anthropomorphic robots, and its kinematics is still taken as an example in several robotic books at the undergraduate as well at the graduate level.

In the meanwhile, other companies developed and manufactured other types of industrial robots. For instance, KUKA developed in 1973 the Famulus robot, whose name in Latin means "servant". In 1974 Cincinnati Milacron, a major machine tool manufacturer, developed a robot called T3 (an acronym for "The Tomorrow Tool"), which was installed in several automotive plants, and especially in the Volvo plants in Sweden. T3 was the first commercially available minicomputer-controlled industrial robot (Figure 5).

In 1974, the Swedish company ASEA (now ABB) started the production of the robots of the famous and successful IRB series, well known worldwide also for their typical orange color. The first robot of this series, that was issued for more than 20 years, was the IRB-6, which was largely employed in productive sites for complex tasks (machining, arc-welding), for its ability to move smoothly along continuous paths (Figure 6).

In the same year, the Japanese company Hitachi developed the robot HI-T-HAND Expert, that is relevant in the history of industrial robotics for the precision it reached in insertion operations (it could insert mechanical parts with a clearance of about 10 micrometers). It was also provided with a force feed-back control system and a flexible wrist mechanism. 


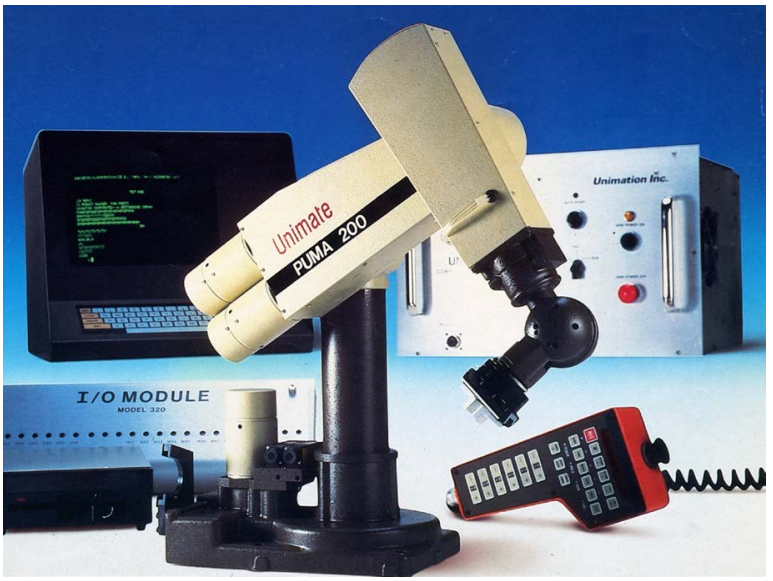

Figure 4. The PUMA robot.

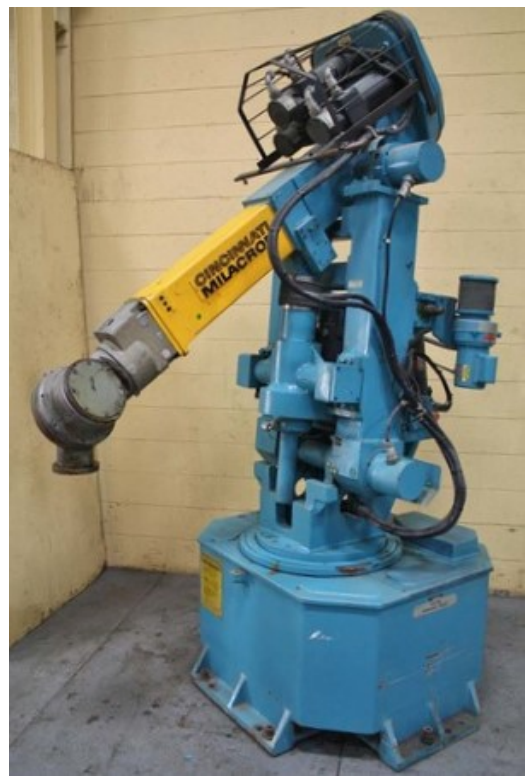

Figure 5. The Cincinnati Milacron T3 robot.

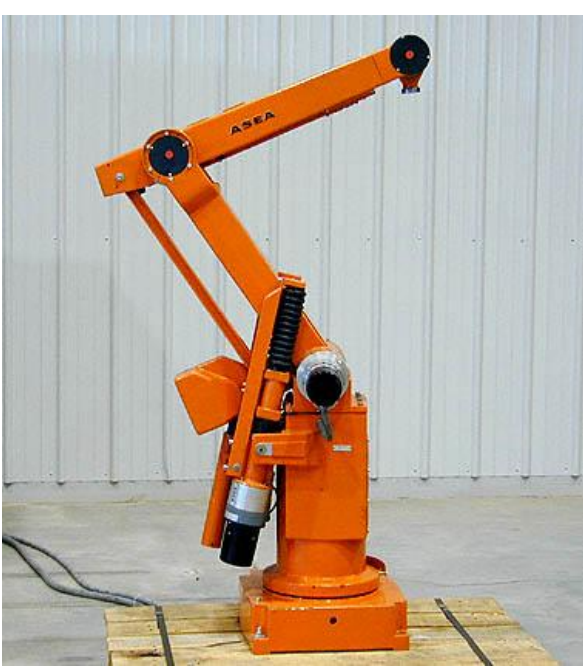

Figure 6. The "legendary" ABB IRB robot. 


\section{The Third Generation of Industrial Robots (1978-1999)}

The industrial robots of the third generation (conventionally ranging from 1978 to 1999) were characterized by a larger extent of interaction with both the operator and the environment, through some kind of complex interfaces (such as vision or voice). They also had some self-programming capabilities, and could reprogram themselves, although by a little amount, in order to execute different tasks (Zamalloa, 2017). These robots were provided with servo controls, and could execute complex tasks, by moving either from point to point or along continuous paths. They could be programmed either on-line (the operator could use a teach box with a keyboard) or off-line, being connected to a PLC or a PC, which allowed to use a high-level language for motion programming and enabled the robots to be interfaced with a CAD or a database. The possibility of high-level, off-line programming enlarged the operational potential of the robots: for in-stance, they could elaborate data from sensor reading, in order to adjust the robot movements taking into account changes in the environment (e.g. changes inposition and orientation of the workpieces). Moreover, the diagnostic capabilities could be greatly enhanced: these robots could produce not only an indication of failure detection, but also a report on the location and on the type of the failure. In addition, some sort of "intelligence" was present in the robots of the third generation, with some (although limited) adaptive capabilities. These capabilities could be employed in some more complex tasks (such as tactile inspection, assembly operations, arc welding), by using the data coming from vision or perception systems to locate the objects and the workpieces and guide the joint movements according to the task to be performed, taking into account the possibility of small changes in the position of the objects.

Between the end of the 1970's and the beginning of the 1980's, other scientific and technical improvements contributed to the diffusion of robots.

In 1978, a novel kinematic structure was proposed by the Japanese scientist Hiroshi Makino from Yamanashi University. Such a structure was made of three revolute joints with parallel axes and a prismatic joint lying at the end of the kinematic chain (Figure 7). The robot with this structure was named SCARA (an acronym from "Selective Compliance Assembly Robot Arm"), since its compliance in the horizontal direction resulted lower than the compliance in the vertical direction. For this reason, as well as for the lightness of the kinematic chain (that allowed a simpler and faster controller), this robot was suitable to be employed in tasks such as the assembly of small objects (Makino \& Furuya, 1980).

Another relevant technical improvement in industrial robotics was the appearance of direct drive actuated robot. The first prototype of this kind was the CMU Direct Drive Arm (Asada \& Kanade, 1983), developed in 1981 by Kanade and Asaka at Carnegie Mellon University (Pittsburgh, USA). This kind of robot featured higher accuracy and faster operations because the motors connected directly to the arms eliminating the need for intermediate gear or chain systems.

Both the aforementioned findings were employed in the AdeptOne (Figure 8), the first commercially available direct-driven SCARA robot (1984). 


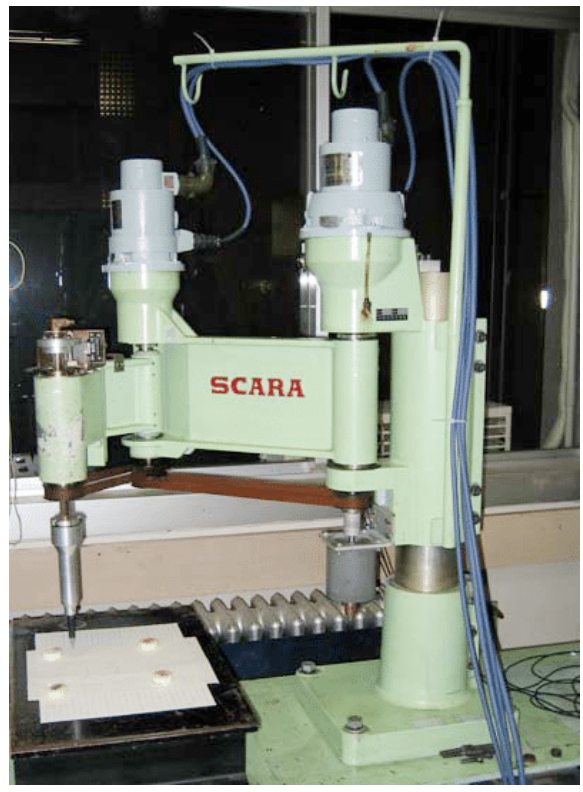

Figure 7. One of the first prototypes of SCARA robot, designed by Hiroshi Makino.

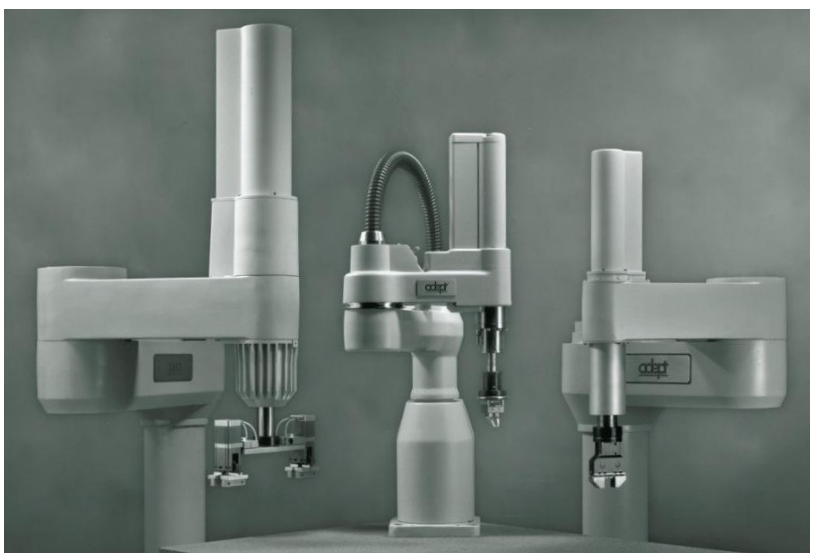

Figure 8. Examples of AdeptOne SCARA robots.

These scientific and technical findings contributed to the diffusion of robots in applications different from those in the classical automotive sector, in particular in the production of consumer goods, especially those in the electronic market. SCARA robots were employed in these types of assembly lines, especially in Japan. For this reason, Japan became in the 1980's not only the world leader in robot manufacturing (with more than 40 companies that built and sold robots worldwide), but also in the production of electronic consumer goods.

Robotics in the 1980's was a rising star, not only in Japan but in all the developed countries. It appeared as a promising field that drew the interest of journalist, scientists, policy makers and also common people.

From the scientific and technical point of view, this is the time when the robots became even more versatile, by exploiting important improvements both with respect to the hardware and the software. Concerning the former aspect, robots started to be provided with advanced sensors (e.g. cameras, force sensors, 
laser scanners); concerning the latter aspects, the control software became more "intelligent" by introducing come techniques related to Artificial Intelligence. Both these aspects increased the versatility and the flexibility of the robots, which could be employed in more and more complex tasks.

Despite the significant progress undergone in the 1980's, the need for robots that could carry out task at high speed pushed the scientific research to design innovative kinematic structures. The idea of employing parallel kinematic chains instead of the classical serial kinematic chains was put forward and led to a type of lightweight robot featuring the capability of moving at high speed. The archetype of this kind of robots was the Delta robot (that appeared in 1992), conceived by the Swiss scientist Reymond Clavel at the Ecole Poly-technique Fédérale de Lausanne (EPFL). This type of robot, designed by Clavel in his $\mathrm{PhD}$ thesis, had three translational DOFs and one rotational DOF (Clavel, 1991). With respect to serial robots, parallel robots featured a smaller work-space, but the capability of operating at much higher speed. The kinematic architecture of the Delta robot was copied in many parallel manipulators, devoted to high speed pick-and-place operations.

The first application of Delta robots was developed by the Swiss company Demaurex in 1992: six Delta robots were operating inside a work cell for loading pretzels into trays (Figure 9). Some years afterwards (1998) ABB developed the Flex-Picker, the world's fastest picking robot, based on the structure of the Delta robot (Figure 10).

In this decade, the first attempts to synchronize robots took place: in 1994 Motoman developed MRC, the first robot control system which provided the synchronized control of two robots (up to 21 axes).

The end of the third generation is conventionally set to the end of the century; beginning from the year 2000, the industrial robots are considered to belong to the fourth generation (which extends up to the current days). Such robots feature high-level "intelligent" capabilities (such as performing advanced computations, logical reasoning, deep learning, complex strategies, collaborative behavior).

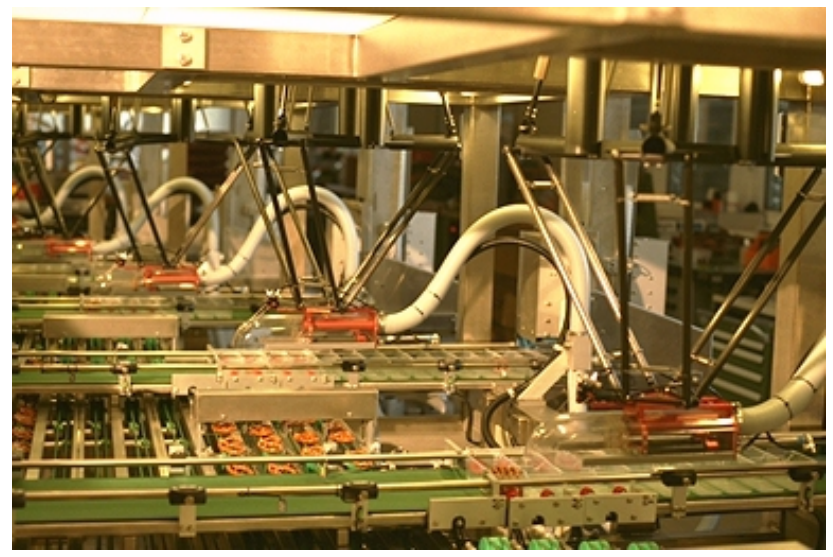

Figure 9. Delta robots in the Demaurex work cells for the packaging of pretzels. 


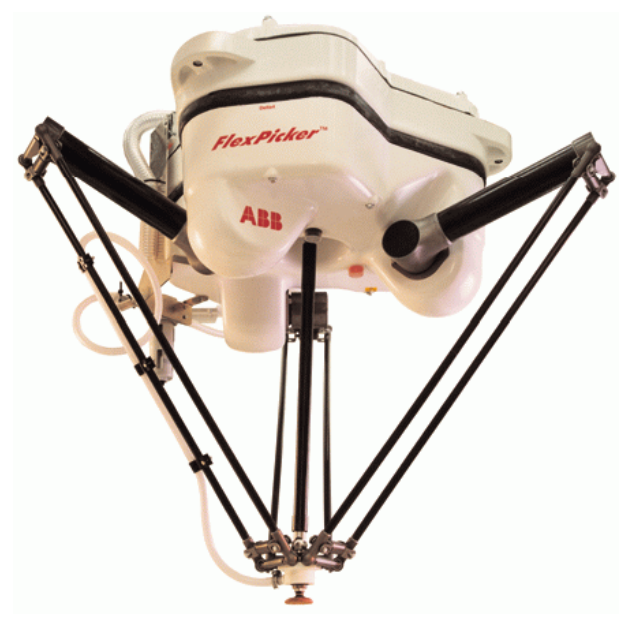

Figure 10. The ABB Flex-Pitcher robot.

\section{Conclusion}

In this paper, a brief history of industrial robotics in the 20th century was presented. The evolution of the industrial robots was conventionally categorized into four generations, of which the first three cover the timespan from the 1950's to the end of the century.

In this historical sketch, not only the scientific and technical evolution was taken into account, but some considerations about the economic and geopolitical issues that determined the diffusion of industrial robots, were also done.

The evolution of industrial robotics is not over, but is still developing in the current days: innovative ideas and novel hardware devices, together with some new programming techniques connected with Artificial Intelligence, are revolutionizing the concept of industrial automation and giving a new youth to the factory environment.

\section{Conflicts of Interest}

The authors declare no conflicts of interest regarding the publication of this paper.

\section{References}

Asada, H., \& Kanade, T. (1983). Design of Direct-Drive Mechanical Arms. Journal of Vibration, Acoustics, Stress, and Reliability, 105, 312-316. https://doi.org/10.1115/1.3269106

Asimov, I. (1942). I, Robot. In Runaround. New York: Spectra Books.

Birnie, J. V. (1974). Practical Implications of Programmable Manipulators. Industrial Robot: An International Journal, 1, 122-128. https://doi.org/10.1108/eb004720

Čapek, K. (2004). R.U.R. Rossum's Universal Robots. Fayetteville: Penguin Ed.

Ceccarelli, M. (2001). A Historical Perspective of Robotics toward the Future. Fuji International Journal of Robotics and Mechatronics, 13, 299-313. https://doi.org/10.20965/jrm.2001.p0299

Ceccarelli, M. (2004). Fundamentals of Mechanics of Robotic Manipulation. Dordrecht: 
Kluwer/Springer. https://doi.org/10.1007/978-1-4020-2110-7

Clavel, R., (1991). Conception d'un robot parallèle rapide à 4 degrés de liberté. Ph.D. Thesis, Lausanne, Switzerland: EPFL.

Devol, G. (1954). Programmable Article Transfer. https://patents.google.com/patent/US2988237

Gasparetto, A. (2016). Robots in History: Legends and Prototypes from Ancient Times to the Industrial Revolution. In Explorations in the History of Machines and Mechanisms. History of Mechanism and Machine Science (vol. 32, pp. 39-49). Berlin/Heidelberg: Springer. https://doi.org/10.1007/978-3-319-31184-5_5

Karlsson, J. M. (1991). A Decade of Robotics; Analysis of the Diffusion of Industrial Robots in the 1980s by Countries, Application Areas, Industrial Branches and Types of Robots. Stockholm, Sweden: Mekanförbundets Förlag.

Koetsier, T. (2019). Towards the Global Intelligent Machine. In The Ascent of GIM, the Global Intelligent Machine. History of Mechanism and Machine Science (vol 36, pp. 293-317). Berlin/Heidelberg: Springer. https://doi.org/10.1007/978-3-319-96547-5

Lagerberg, T., \& Jonson, J. (2016). Une bio du robot. Petite histoire de la robotique industrielle. ABB Review 3/16. http://new.abb.com/about/technology/abb-review

Makino, H., \& Furuya, N. (1980). Selective Compliance Assembly Robot Arm. Proceedings of 1st International Conference on Assembly Automation (ICAA), Brighton, March 25-27, 77-86.

Malone, B. (2011). George Devol: A Life Devoted to Invention, and Robots. IEEE Spectrum Magazine.

https://spectrum.ieee.org/automaton/robotics/industrial-robots/george-devol-a-life-de voted-to-invention-and-robots

Mathia, K. (2010). Robotics for Electronics Manufacturing. Principles and Applications in Clean-room Automation. Cambridge: Cambridge University Press.

https://doi.org/10.1017/CBO9780511712173

Scheinman, V. (1973). Design of a Computer Controlled Manipulator. PhD Thesis, Stanford, CA: Stanford University. http://www.dtic.mil/docs/citations/AD0708069

Siciliano, B., \& Khatib, O. (2008). Springer Handbook of Robotics. Berlin Heidelberg: Springer-Verlag.

Wallen, J. (2008). The History of the Industrial Robot. Technical Report, Linköpings: Automatic Control at Linköpings Universitet.

http://www.control.isy.liu.se/publications

Westerlund, L. (2000). The Extended Arm of Man-A History of the Industrial Robot. Stockholm: Informationsförlaget.

Zamalloa, I., Kojcev, R., Hernandez, A., Muguruza, I., Usategui, L., Bilbao, A., \& Mayoral, V. (2017). Dissecting Robotics_Historical Overview and Future Perspectives. 